\title{
MOBILE LEARNING :: A GLOBAL CONTEXT
}

\author{
*Dr. P. Saritha
}

\section{Introduction}

Mobile learning ( $m-$ Learning) has different meanings for different communities. Although related to e-learning and distance education, it is distinct in its focus on learning across contexts and learning with mobile devices. One definition of mobile leaming is "any sort of learning that happens when the learner is not at a fixed, predetermined location or learning that happens when the learner takes advantage of the learning opportunities offered by mobile technologies". in other words, mobile learning decreases limitation of learning location with the mobility of general portable devices. The term covers learning with portable technologies, where the focus is on the technology; learning across contexts and learning in a mobile society, with a focus on how society and its institutions can accommodate and support the learning of an increasingly mobile population that is not satisfied with existing learning methodologies. M-learning is convenient in the sense that it is accessible from virtually anywhere, which provides access to all the different learning materials available. It is also collaborative; sharing is almost instantaneous among everyone using the same content, which leads to the reception of instant feedback and tips. M-Learning also brings strong portability by replacing books and notes with small RAMs, filled with tailored learning contents. In addition, this kind of learning is engaging and fun. Therefore, it is simple to utilize mobile learning for a more effective and entertaining experience.
For years, learning analysts have been predicting wide adoption for mobile learning. But, until now, this has not occurred. The adoption of mobile learning has been constrained by slow networks, limited services, anemic devices, and hesitancy by organizations to purchase hardware that could soon be obsolete. All of this is now changing. $M$ learning is taking off because the access devices, mobile phones are already in people's pockets. In addition, the phones are owned by the learners, not by institutions or large organizations. This makes an enormous psychological difference in terms of learners viewingthemselves as being in control of their own learning.

\section{HISTORY OF MOBILE LEARNING}

\section{0s and 1980s}

Alan Kay and colleagues in the Learning Research Group at Xerox Palo Alto Research Center [PARC] propose the Dynabook as a book-sized computer to run dynamic simulations for learning. Their interim Dynabooks are the first networked workstations.

\section{0 s}

Universities in Europe and Asia develop and evaluate mobile learning for students. Palm Corporation offers grants to universities and companies who create and test the use of Mobile Learning on the Palm OS platform. Knowledge creates the first mobile learning modules for CCNA, At and MCSE certification using the core tools that later became LMA.

* Assistant Professor, Department of Business Administration, Yogi Vemana University, Kadapa - 516003, A.P. India. 


\section{0 s}

The European Commission funds the major multinational MOBllearn and M-Learning projects.

\section{Growth of M-Learning}

Over the past ten years mobile learning has grown from a minor research interest to a set of significant projects in schools, workplaces, museums, cities and rural areas around the world. The $m$-Learning community is still fragmented, with different national perspectives, differences between academia and industry, and between the school, higher education and lifelong learning sectors.

\section{Current areas of growth include :}

* Testing, surveys, job aids and just in time learning

- Location-based and contextual learning

* Social-networked mobile learning

* Mobile educational gaming

* "Lowest common denominator" $\mathrm{m}$-Learning to cellular phones using two way SMS messaging and voice-based Cell Casting.

According to a report by Ambient Insight in 2008, "the US market for Mobile Learning products and services is growing at a five-year compound annual growth rate (CAGR) of $21.7 \%$ and revenues reached $\$ 538$ million in 2007 . The data indicate thiat the demand is relatively immune from the recession". The findings of the report indicate that the largest demand throughout the forecast period is for custom development services, content conversion, media services and that the healthcare sector accounts for $20 \%$ of the total US market for mobile learning.

\section{SCOPE OF MOBILE LEARNING}

The scope of mobile learning includes :

$>$ Children and students using handheld computers, PDAs or handheld voting systems in a classroom or lecture room.
$>$ Students using mobile devices in the classroom to enhance group collaboration among students and instructors using a Pocket PC.

$>$ On the job training for someone who accesses training on a mobile device "just in time" to solve a problem or gain an update.

$>$ Learning in museums or galleries with handheld or wearable technologies.

Learning outdoors, for example on field trips.

$>$ The use of personal technology to support informal or lifelong learning such as using handheld dictionaries and other devices for language learning. Mobile Assisted Language Learning (MALL) is a term used to describe application of handheld computers or cell phones to assist in language learning.

> Improving levels of literacy, numeracy and participation in education amongst young adults.

$>$ To provide audiovisual support in order to enhance training that has been provided in a corporate business or other class room environment.

Using the communication features of a mobile phone as part of a larger learning activity. For eg., sending media or texts into a central portfolio, or exporting audio files from a learning platform to your phone.

$>$ Class management especially for distance education or students whose course requires them to be highly mobile through text SMS notices regarding availability of assignment results, venue changes and cancellations and the like.

$>$ Continuous learning and portable tools for military personnel. 


\section{Areas of M-LEARNING}

Companies were formed that specialize in three core areas of mobile learning.

$>\quad$ Authoring and publishing
$>\quad$ Delivery and Tracking
$>\quad$ Content Development

Conferences and trade shows were created to specifically deal with mobile learning and handheld education, including: m-Learn, WMUTE and IADIS mobile learning international conference series, ICML in Jordan, Mobile Learning in Malaysia, Handheld Learning in London, SALT Mobile in USA.

\section{VALUE OF MOBILE LEARNING}

The tutors commented on the value of mobile learning as follows:

- It is important to bring new technology into the classroom.

- Mobile learning could be utilised as part of a learning approach which uses different types of activities (or a blended learning approach).

- Mobile learning supports the learning process rather than being integral to it.

- Mobile learning needs to be used appropriately according to the groups of students involved.

- Mobile learning can be a useful add-on tool for students with special needs. However, for SMS and MMS this might be dependent on the students' specific disabilities or difficulties involved.

- Good IT support is needed.

- Mobile learning can be used as a 'hook' to re-engage disaffected youth.

- It is necessary to have enough devices for classroom use.

\section{TECHNOLOGIES USED IN M-LEARNING}

Most personal technologies can support mobile learning, including

- Personal Digital Assistant in the classroom and outdoors

- Tablet PC, UMPC, mobile phone, camera phone and Smart Phone

* Learning Mobile Author, e.g., for authoring and publishing WAP, Java ME and SmartPhone

* Personal audio player, e.g., for listening to audio recordings of lectures

- Handheld audio and multimedia guides in museums and galleries

- Handheld game console, modern gaming consoles such as Sony PSP or Nintendo DS.

Technical and delivery support for mobile learning:

- 3GP For compression and delivery method of audiovisual content associated with Mobile Learning

- Wi-Fi gives access to instructors and resources via Internet

- GPRS mobile data service, provides high speed connection and data transfer rate.

\section{NEED OF MOBILE DEVICES FOR LEARNING}

Most mobile devices are useful in education as administration, organisation and teaching aids for practitioners and also as learning support tools for learners. Here are some of the main benefits:

- Learners can interact with each other and with the practitioner instead of hiding behind large monitors. 
- It's much easier to accommodate several mobile devices in a classroom than several desktop computers.

- PDAs or tablets holding notes and e-books are lighter and less bulky than bags full of files, paper and textbooks, or even laptops.

- Handwriting with the stylus pen is more intuitive than using keyboard and mouse.

- It's possible to share assignments and work collaboratively; learners and practitioners can e-mail, cut, copy and paste text, pass the device around a group, or "beam" the work to each other using the infrared function of a PDA or a wireless network such as Bluetooth.

- Mobile devices can be used anywhere, anytime, including at home, on the train, in hotels - this is invaluable for work-based training.

- These devices engage learners - young people who may have lost interest in education - like mobile phones, gadgets and games devices such as Nintendo DS or Play station Portable.

- This technology may contribute to combating tre digital divide, as this equipment (for example PDAs) is generally cheaper than desktop computers.

\section{Accessibility and M-Learning}

The size, shape, weight and portability of mobile devices make them particularly effective for users with disabilities. The organiser functions usually included in mobile devices are extremely useful for learners with learning difficulties to help them organise their lives and achieve some independence. PDAs often also incorporate dictionaries and thesauruses, which provide handy reference tools for learners with dyslexia or other learning difficulties. Tablet PCs include text-tospeech and voice recognition as standard tools, which are valuable for users with disabilities or leaming difficulties. The devices can also be attached to wheelchairs with the use of small brackets.

However, many of the other features are not so user friendly. For instance, the small buttons can be difficult for people with little manual dexterity to manipulate. The stylus pens are often narrow and small, and require accurate use to work correctly. You can purchase attachable keyboards for PDAs, but these are also quite small, and options for switch or mouse access are limited. They can be also being a little flimsy. The small screen sizes of PDAs and mobiles are not ideal, as the display tends to be cramped, which is unhelpful for people with dyslexia and other learning difficulties. The restricted functionality of the operating systems used by PDAs also adds to the problems, as users with disabilities need to be able to customise colour, text size and font.

\section{Parameters for M-Learning}

There are five basic parameters for production and development of m-learning and they are:

\section{Portable}

If a person is using a mobile phone or a PDA, then it's easier to carry it along with him everywhere including the restroom. This makes information access through this platform easy and fast.

\section{Social Interaction}

This kind of data can be sent to any friends, colleagues and others via short messages. Everybody can exchange data with other people and gain considerable knowledge.

\section{Sensitive to the Context}

This has a capability of gathering data unique to the current location, environment, and time. This includes both types of data - real and simulated. 


\section{Connectivity}

Connectivity plays an extremely important role and is the backbone of the m-learning project. With the help of a strong connectivity network, one can connect to data collection devices, other mobile phones and to a common network.

\section{Customized}

The most unique capability is to be able to offer customized learning information.

\section{ADVANTAGES OF M-LEARNING}

- Its offers and interactive learning experience where learners can interact with each other.

- It's easier to accommodate several mobile devices in a classroom than several desktop computers.

- It is not always easy to work on a computer sitting in a far off village or town in wilderness, but mobile can be accessed anywhere.

- Mobile phones, PDAs or tablets holding notes and e-books are lighter and can facilitate the entire m-learning process with ease unlike bags full of files, paper and textbooks or even laptops.

- Writing with the stylus pen is more effective than using keyboard and mouse.

- A range of possibilities arise out of this like sharing assignments and working as a group; learners and practitioners can e-mail, copy and paste text or even 'beam' the work to each other using the infrared function of a PDA or a wireless network such as Bluetooth.

- Mobile devices can be used anywhere and anytime including at offices, home or when in transit.

- These devices engage learners through mobile phones, gadgets and games devices such as Game Boys. This makes the device invaluable.
- This technology may contribute to combating the digital divide as mobile devices are generally cheaper than desktop computers.

- The size, shape, weight and portability of mobile devices have made them extremely effective for users with permanent or temporary disabilities.

\section{DISADVANTAGES OF M-LEARNING}

* Small mobile and PDA screens limit the amount and type of information that can be displayed.

- There are limited storage capacities for mobiles and PDAs.

* Batteries have to be charged regularly, and data can be lost if this is not done correctly.

* They can be much less robust than desktops.

* It's difficult to use moving graphics especially with mobile phones, although $3 G$ and $4 G$ will eventually allow this.

- It's a fast-moving market, especially for mobile phones, so devices can become out of date very quickly.

- Bandwidth may degrade with a larger number of users when using wireless networks.

- The small screens of a mobile or PDA limits the amount and type of information that can be displayed at a given time.

- The memory or the storage capacity is limited vis-à-vis a computer or laptop.

- It is important to have fully functional devices and batteries have to be charged regularly. At times, a discharged battery can result in loss of important data.

* It's difficult to work on moving graphics, especially on mobile phones, although $3 G$ and $4 G$ will eventually facilitate this.

- Bandwidth may degrade with increasing users when using wireless networks. 


\section{Challenges of $M$ - Learning}

Technical challenges include:

$>$ Connectivity and battery life,

$>$ Screen size and key size,

$>$ Ability for authors to visualize mobile phones for delivery,

$>$ Multiple standards, multiple screen sizes, multiple operating systems and

$>$ Repurposing existing e-Learning materials for mobile platforms

Social and educational challenges include:

$\checkmark \quad$ Accessibility and cost barriers for end users,

$\checkmark$ How to assess learning outside the classroom,

$\checkmark$ How to support learning across many contexts,

$\checkmark \quad$ Developing an appropriate theory of learning for the mobile age,

$\checkmark \quad$ Conceptual differences between e-and m-learning,

$\checkmark$ Design of technology to support a lifetime of learning,

$\checkmark \quad$ Tracking of results and proper use of this information,

$\checkmark \quad$ No restriction on learning timetable,

$\checkmark \quad$ ?ersonal and private information and content,

$\checkmark \quad$ No demographic boundary,

$\checkmark$ Disruption of students' personal and academic lives and

$\checkmark$ Access to and use of the technology in developing countries.

\section{FUTURE OF M-LEARNING}

Technologies currently being researched for mobile learning include:

- Location aware learning,

- Point-and-shoot learning with camera phones and $2 \mathrm{D}$ codes,

* Near Field Communications (NFC) secure transactions,

- Sensors and accelerometers in mobile devices in behavioral based learning,

- Mobile content creation,

* Games and simulation for learning on mobile devices and

- Context-aware ubiquitous learning,

\section{CONCLUSION}

Learning something from a small cell phone screen is different than reading a book or browsing through an online learning application. Although most people would prefer the traditional way of learning when the conditions are appropriate, mobile learning has the great advantage of accompanying the student everywhere. Mobile learning may currently be most useful as a supplement to ICT, online learning and more traditional learning methods and can do much to enrich the learning experience. It is widely believed that mobile learning could be a huge factor in getting disaffected young adults to engage in learning, where more traditional methods have failed. As mobile phones combine PDA functions with cameras, video and MP3 players and as tablets combine the portability of PDAs with the functionality of desktops, the world of learning becomes more mobile, more flexible and more exciting. 


\section{REFERENCES}

1. Adkins, S.S. (December 2008). "The US Market for Mobile Learning Products and Services:20082013 Forecast and Analysis", Ambient Insigh, Dec, 2008.

2. http://mww.ambientinsight.com/Resources/Documents/AmbientInsight 2008

3. Maniar, N.; Bennett, E., Hand, S. \& Allan, G, "The effect of mobile phone screen size on video based learning". Journal of Software 3 (4), pp 51-61,2008.

4. Sharples, M., "The design of personal mobile technologies for lifelong learning". Computers \& Education 34, pp.177-193, 2000. 